\title{
Approach to Analysis and Assessment of ERP System. A Software Vendor's Perspective
}

\author{
Ilona Pawełoszek \\ Częstochowa Univeristy of \\ Technology, Management Faculty \\ Poland \\ Email: ipaweloszek@zim.pcz.pl
}

\begin{abstract}
The paper presents an approach to analysis and assessment of benefits brought by an implementation of an Enterprise Resource Planning system. The research has been conducted on a sample of 10 Polish companies using the Xpertis software, which is one of the popular applications for supporting the business activities of small and medium companies. The approach presented hereby aims at elaboration of the assessment method which can be easily applied by the software vendor, moreover it is acceptable by the customers because it does not disclose the confidential business information and still gives the results informative enough to be valuable as well for the software company as for its customers. Cluster analysis conducted through the Orange Data Mining tool was proposed as a technique of data analysis. The comparative study of the Xpertis ERP features and the customers' characteristics has been briefly presented and the directions of the future development of the considered software have been proposed.
\end{abstract}

\section{INTRODUCTION}

$\mathrm{T}$ HE Assessment of benefits brought by an implementation of an ERP system is important from the point of view of two groups of stakeholders. The first group are companies which choose to use the system, incur costs of its implementation and maintenance. The other group's members are the system creators and vendors for which the system is a commodity for sale and a product covered by information and promotion campaigns. The aims of both groups of stakeholders - vendors and buyers - are somehow similar. In both cases there is a need for a forecast how the implementation of integrated information system will influence the functioning of the user-company in different areas. That information is crucial for a customer who buys the ERP system and wants to know how successful the investment will be and whether it will bring him operational effectiveness and competitive advantage. On the other hand the ERP vendors are strongly interested in effectiveness and usability of their system to use that knowledge in further development of their product and improvement of the level of their services (customer support, training, helpdesk applications etc.).
The domain of information systems analysis and assessment is a broad field related to many aspects of the company's functioning. The ERP assessment issues are well grounded in the literature, however most of the approaches represent the customer's perspective.

The critical success factors (CSFs) for an ERP implementation, with the number of over 80 [17] have been well documented in the literature [13]. The factors such as: top management support, project team competence, interdepartmental cooperation, clear goals and objectives, project management, are considered to be monitored during the implementation of the system. [21]. But the question arises how to assess the system that has already been implemented and in the same time to check whether the successful implementation directly translates into the overall performance of the system during the consecutive years of its exploitation [11]

The main problem that confronts the current measurement frameworks is the fact that much of the benefits are strategic, therefore they are hard to quantify and may only appear several years after the implementation of the solution [4].

The aim of this paper is to present an approach that can be taken by software companies to create a method for evaluation of their products in terms of customer needs and identification of areas for the product's improvement.

The presented approach aims at bringing relevant and informative results that can also be presented to future customers to show them the usefulness of the system and reduce the information asymmetry which is cited as an important factor of ERP implementation failure [23]. The approach used in this study is based on the example of Xpertis ERP system offered by Macrologic Inc.

The structure of the paper is as follows. Section 2 introduces context for the study which is rooted in Polish market of ERP systems. The main focus has been on small and medium software companies and the issues they face in competing on highly demanding Polish market. Section 3 briefly describes the problems of ERP evaluation from the vendors perspective with special focus on software usability 
and sustainability. Section 4 provides the description of research approach and design. Section 5 presents the data analysis approach based on clustering methods. Sections 6 and 7 present the research results, respectively the system features and the customers' characteristics. The conclusion section summarizes the outcome of the work, and suggests future research directions.

\section{THE POLISH MARKET OF ERP}

ERP systems today grow in popularity and importance among enterprises of all sizes. For today's companies the support from well-tuned IT solution seems absolutely necessary although according to Central Statistical Office of Poland the share of Polish companies using ERP was only $18 \%$ in the year 2013 and grew to $22 \%$ in 2014, which is around $9 \%$ points less than average for $28 \mathrm{EU}$ countries. [2]

Most of the small and medium Polish companies built their own systems (almost $40 \%$ of manufacturers with 100 to 1000 employees) or do not have the integrated IT system at all. The lack of integrated enterprise system hinders and delays information flow within an organization because the data is kept in many loosely coupled applications. Such a situation negatively impacts the company's competitiveness [14].

An analysis of the numerous reports from ERP market brings the reader to the conclusion that the market capacity is high. The potential target group are small and medium companies that do not have the ERP, but also large companies that need to replace or modernize their legacy system.

However the survey among managers of the Polish SME companies reveals little awareness of the need to implement the ERP and its impact on the company's profitability (only $33 \%$ of respondents declared to see the need to implement the ERP system) [24].

Many companies complain that after their huge investments in ERP systems, they find the systems do not bring the expected results in terms of new orders, new profits, or competitive advantage. [8]

For the majority of small and medium enterprises the decision of adoption as well as the selection of the appropriate ERP system is a difficult task. The main issues are shortage of financial resources, limited qualified IT personnel, lack of resources and time have been cited as the main factors that make this task difficult and risky [22]

The Polish ERP market is a very competitive one. There was 31 ERP vendors in Poland in 2014. The unquestionable market leader is SAP (39.6\% share), which is followed by Comarch, Oracle, IFS and BPSC. The remaining market share of around $26 \%$ is divided among other small companies one of which is Macrologic Inc..

Large companies own enough financial and managerial resources to develop and bring to market new software products and to gain dominant share of the market. Contrarily, small software companies often meet difficulties in finances and staffing while running their businesses. Therefore they often choose to concentrate on a market niche, which is disregarded by large companies. Small companies also opt to build their competitive advantage mainly on the basis of their excellent responsibility and flexibility.

Actually, due to the limitation of resources faced by small and medium companies best practices which have proven in large firms might be too expensive or time consuming to perform. Accordingly, the recent researches start to find specific solutions to improve small companies' software processes in several aspects. [19]

\section{The Problems of ERP EVAluation From the VENDORS' PERSPECTIVE}

The software systems today are more than just a commodity, they are strategic asset custom tailored to the issues each company is facing. They provide the ability to precisely adapt the software components to the needs of the organization. They are characterized by the requirement to provide maximum flexibility, understood primarily as a possible use by a variety of organizations [26].

Due to the complexity of enterprise systems, bringing a new product to the market is both expensive and risky for the vendor. Initial investment requires both highly skilled human effort, time and specialized IT tools. A software packages ERP life cycle has two linked segments: vendor's and customer's. The vendor's segment includes phases: analysis, design, developing and maintenance [27]. While planning and developing a new software product it is necessary to anticipate its complete lifecycle which is of even 10 to 20 years of exploitation. During its lifetime the ERP system needs to be securely operated, patched, upgraded, extended and integrated with other systems, and still preserve the functional requirements of the end-users.

From the marketing point of view, one of the most important factors is usability of the ERP system, which, according to ISO Standards can be viewed as a set of three factors: effectiveness, efficiency and satisfaction [10]. While users' satisfaction is quite easy to asses by asking the users for their opinion, there is more confusion when it comes to actually measure the system's efficiency or effectiveness especially in economic terms. It is hard to say to what degree the system impacts the overall performance of a company. Moreover the values to be measured are dynamic and change with the time that has elapsed since the completion of implementation.

Usability can be also described in narrower sense as a set of three following criteria [20]: navigation, presentation and learnability. Navigation is about accessing the information easy and finding system's functions by using the elements of the user interface. Presentation is the feature describing visual layout of the screen and the layout of printed documents. The layout of the interface elements such as 
menus, dialog boxes and controls should be logically structured and legible. Learnability is the most tricky to asses because it highly depends on other non-system issues such as users' skills, technical background, previous experiences with similar systems etc. Learnability can be measured as time needed to get basic knowledge to work with the system. Learnability is associated with accessible online or offline help files and additional training offered by the vendor. Learnability can be also measured as the degree of ease to learn how to use the system effectively, however this measure is very subjective. It often happens that the first implementation of the ERP system in a given company requires changes in business processes in such case the users can report difficulties in understanding the system as it does not correspond with the processes they are used to.

Security and reliability are also important issues that the vendor should be able to assess. This can be done by collecting data from system logs, especially those associated with error events. The events recorded by an ERP system should be semantically interpreted to find out the direct or indirect causes of failures.

In recent years, increasing environmental and social concerns posed a new challenge to the software vendors to improve sustainability of their products. Sustainability in broader perspective (in contrast with the narrow focus on reducing emissions of carbon dioxide) covers all aspects that potentially impact the use of any limited resource. Many resources in software development and operation can be considered as limited ones, for example: the number and expertise of administrators, the time of end users getting used to software or fulfilling a certain task, the available hardware etc., Sustainable software takes these constraints into account and balances them with the value added by the software [6].

The factors of sustainability are hard to predict and it is only during the exploitation phase that they can be determined. The evaluation of the system always requires cooperation of the stakeholders in determining where the highest probabilities of weak points exist. These observations are valuable as well for the vendor to gain knowledge about the products as for customers to help them improve their businesses.

\section{RESEARCH APPROACH AND DESIGN}

The aim of the study was to evaluate the impact of the ERP system on different areas of the company where the system is supposed to bring improvements in comparison to the situation before the system implementation. The studied product was the ERP system Xpertis developed by Macrologic Inc.. The system has been chosen as the object of the study due to the fact that it is exploited for educational purposes at Czestochowa University of Technology and so the author, working as an educator, had a chance to get familiar with its functions and business logic. The other important aspect is the pro-innovative attitude of the
Macrologic's Executives who are substantially interested in continuous improvement of their product and competitiveness on the demanding Polish enterprise software market. The company is searching for new approaches to get valuable product and customer knowledge. These two kinds of knowledge are closely related to each other.

Product knowledge is an essential sales skill. The software manufacturer and vendor have their own subjective view of the product. To get the whole picture of the complex software product it is necessary to consider the customer's perspective. Moreover by acquiring the customers' knowledge the vendor gains deep understanding of the product features that allows the vendors to present the benefits accurately and persuasively. Customer knowledge is an essential asset since it represents a source of customer value improvement [5].

The market of ERP systems is overloaded with a lot of competitors offering very similar products. Therefore it can be hard to recognize the differences between them as well for the customer as for the vendor. In this situation the competitive advantage can be found in the way of communicating with the future and existing customers. The key element of communication seems to be the way of presenting them a value proposition. In marketing, a customer value proposition consists of the total sum of benefits which a vendor promises a customer will receive in return for the customer's associated payment [9].

Customers are a brilliant source of knowledge for the companies, because they gain expertise while using products or services [7]. However gaining customer knowledge is a difficult task. Survey practitioners often experience difficulties in collecting reliable data due to various privacy concerns. The exposed problem is mentioned in many publications. Some of the companies refuse to take part in the survey as their company policy do not allow sharing internal information with outsiders even for academic purposes [18]. Companies are afraid to conduct the research because it could reveal weaknesses in the management process, which are known but ignored by the executives of these companies [12]. Some of the companies' excuse for not taking part in the surveys is that the studies do not seem to bring any value for the respondents. To avoid such situation the goal of the study should be clearly defined and the utility value for the respondents should be the communicated at first.

The presented approach to analysis and assessment of ERP systems addresses the problem of commerciallysensitive information. This could be achieved through an adequate design of the survey questionnaire.

The approach, although it is tailored to fit the needs of the Macrologic Inc. and the Xpertis ERP, can be used by other software companies offering similar systems after some necessary modifications of the survey questionnaire according to the specificity of their product. 
The survey has been conducted on the sample of 10 Polish companies, who have recently (during the past three years) completed the implementation of the Xpertis system. The participants for the survey were selected using a non-random decision rule intended to select the set of companies who satisfy the following conditions:

- The surveyed companies localized in different cities representing at least $50 \%$ of Polish voivodeships (administrative districts).

- The Company's management board's permission for the employees to undergo the survey.

- The Companies differentiated throughout the branches of industry (furniture, metallurgic, chemical, foundry, services and other).

- There were usually 7-10 persons who were surveyed in each of the companies. The persons are employees who are directly involved in operating the selected system's modules.

The survey questions were brainstormed by the team of three IT and management experts, all of them having experience in using the considered ERP.

The responders were employees operating the system in their daily work. They were asked to evaluate the impact of the system using the Likert-type scale from -2 to 2 (presented in Table I). The lack of evaluation were also allowed in cases when particular question was not relevant to the scope of the company's activities.

The reasons for the choice of the Likert scale instead of concrete values were twofold:

- the chosen scale is easy to interpret and compare
11. Accounting and finance

The questions for all the aforementioned areas are organized into 3 categories and subsequent factors:

1. General factors:

- Compliance with the business requirements (Preimplementation analysis)

- Compliance with business strategy

- functional adjustment to the business process specificity

2. User interface factors and usability factors:

- Overall satisfaction of the user

- Ease of use

- Functional adjustment to the user's tasks

- User friendliness of the interface

- User assistance in problem solving

- User's autonomy (necessity of the system's administrator assistance)

- Visual attractiveness of the printed documents

3. Specific factors - different for each area of company, associated with specific business operations.

The dataset yields a matrix containing 10 units of observation, each one is described by 205 factors..

The first aim of analysis was to extract the factors which are important and influence the functioning of the Xpertis ERP system, usability and effectiveness of the users' work and at the same time eliminating those factors which appear to be irrelevant (mainly assessed as 0 and ND)

The second aim was to find similarities between evaluations made by 10 surveyed companies. These similarities and differences can be useful to create the

TABLE I.

RATING SCALE AND ITS INTERPRETATION

\begin{tabular}{|c|c|c|c|c|c|}
\hline $\begin{array}{c}\text { Very bad/significant } \\
\text { deterioration }\end{array}$ & $\begin{array}{c}\text { bad/ } \\
\text { deterioration }\end{array}$ & $\begin{array}{c}\text { neutral/ } \\
\text { no changes }\end{array}$ & $\begin{array}{c}\text { good } \\
\text { /improvement }\end{array}$ & $\begin{array}{c}\text { Very good/significant } \\
\text { improvement }\end{array}$ & $\begin{array}{c}\text { Not } \\
\text { applicable* }\end{array}$ \\
\hline-2 & -1 & 0 & 1 & 2 & NA \\
\hline
\end{tabular}

* The answer in case the given ERP module was not implemented or the company does not operate in the given area.

Source: Own elaboration

because the values are normalized,

- the Likert-type scale was acceptable to the surveyed companies as a form of the survey that does not disclose their detailed financial and operating information.

The survey questions covered 11 areas of the organization's activity:

1. Production - execution of orders

2. Sales

3. After-sales services

4. Recycling

5. Marketing

6. Procurement

7. Warehouse management

8. Economic analyses

9. Organization

10. Human resources and payroll, profiles of features and needs of different groups of customers. This research will allow to get knowledge about the needed future adjustments of the ERP system to the customers' needs.

\section{V.DATAANALYSIS METHOD}

The analysis could be performed on an intuitive way by a simple method of screening the data and selecting those factors which received the highest and the lowest scores in the customers' opinions. However establishing a more detailed approach to the classification of important features of ERP can be performed through the means of datamining as it offers statistically based methods for identification of patterns in data sets.

For the considered dataset cluster analysis seems to be the appropriate choice because it allows to identify groups of 
similar records and moreover it is a well described and investigated method that is still being developed and ameliorated up till today [15].

Cluster Analysis or clustering is a common technique of statistical data analysis - specifically unsupervised machine learning. The objective of clustering is to assign observations to the groups (called clusters) in a way that the observations in the same cluster are similar to one another in some sense.

There are many clustering methods based on various algorithms that can be applied depending the nature of the dataset under consideration. Different clustering algorithms may render different results on the same data. Moreover the same clustering algorithm may bring different results on the same data, if it involves arbitrary initial parameters.
However interpreting the results of cluster analysis is not a trivial task, because it requires knowledge of semantic relations between investigated attributes of the ERP system and the domain it supports.

There are three important steps in the preparation of cluster analysis:

1. Selecting a distance measure - The similarity between various objects is defined by a distance measure. The distance measure plays an important role in obtaining semantically meaningful clusters. For simple datasets where the data is multidimensional, Euclidean distance measure can be employed. [25]. Moreover the Euclidean distance is appropriate for data measured on the same scale, as in this case.

TABLE II.

THE STATISTICS OF THE CLUSTERS

\begin{tabular}{|l|l|l|l|l|l|l|l|}
\hline \multirow{2}{*}{ Cluster } & \multirow{2}{*}{$\begin{array}{c}\text { Number } \\
\text { of features }\end{array}$} & \multicolumn{6}{|c|}{ Evaluation } \\
\cline { 3 - 8 } & & $-\mathbf{- 2}$ & $-\mathbf{- 1}$ & $\mathbf{0}$ & $\mathbf{1}$ & $\mathbf{2}$ & \multicolumn{1}{c|}{ ND } \\
\hline cluster 0 & 87 & $0,0 \%$ & $0,0 \%$ & $11,1 \%$ & $31,7 \%$ & $55,1 \%$ & $2,1 \%$ \\
\hline cluster 1 & 13 & $0,0 \%$ & $0,0 \%$ & $7,7 \%$ & $12,3 \%$ & $78,5 \%$ & $1,5 \%$ \\
\hline cluster 2 & 36 & $0,3 \%$ & $0,3 \%$ & $32,1 \%$ & $37,6 \%$ & $18,7 \%$ & $2,0 \%$ \\
\hline cluster 3 & 36 & $3,3 \%$ & $0,3 \%$ & $0,6 \%$ & $75,6 \%$ & $19,4 \%$ & $0,8 \%$ \\
\hline cluster 4 & 11 & $2,7 \%$ & $4,5 \%$ & $50,9 \%$ & $34,5 \%$ & $0,9 \%$ & $6,4 \%$ \\
\hline cluster 5 & 22 & $0,0 \%$ & $0,0 \%$ & $19,1 \%$ & $3,6 \%$ & $0,0 \%$ & $77,3 \%$ \\
\hline sum & 205 & & & & & & \\
\hline
\end{tabular}

* The answer in case the given ERP module was not implemented or the company does not operate in the given area.

Source: Own elaboration

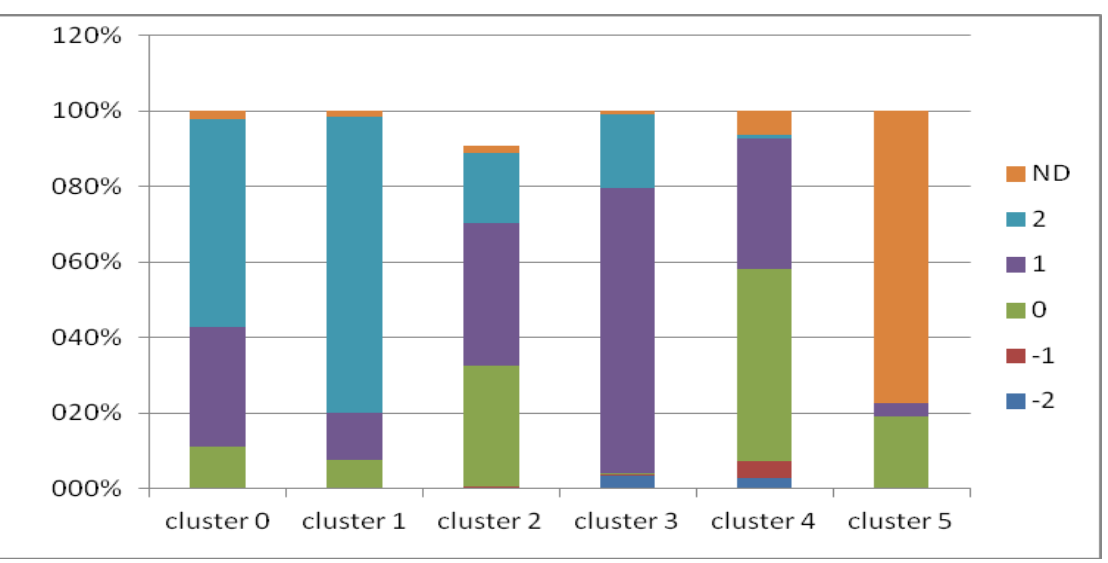

Fig. 1 Visualization of feature clusters statistics; Source: Own elaboration

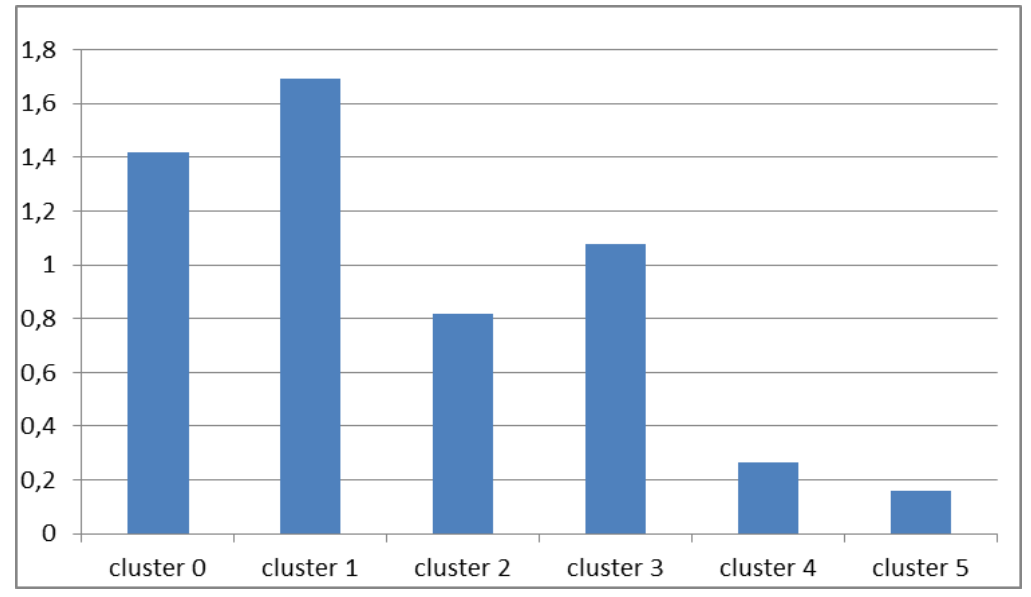

Fig. 2 Average evaluation for each cluster; Source: Own elaboration 
2. Choosing clustering method and tool. A Hierarchical clustering method has been applied to classify the data set. The clustering algorithm were used and analyses were performed with Orange 2.7.1 software (developed by developed by Bioinformatics Lab at University of Ljubljana, Slovenia, in collaboration with open source community [3].

3. Determining the number of clusters in a data set. It is still an open problem in the machine-learning research community. There is no generally recognized state of the art statistical method to set the right number of clusters. The heuristics, rule of thumb can be recommended instead. The most important rule is to preserve an informative value of the clusters. Each of the clusters should have its own general characteristics differing from the others.

In the present case the cluster analysis can be applied to two purposes:

- to distinguish groups of the features which received similar ratings from the customers using the Xpertis ERP system. For this analysis data matrix should be prepared with the column names indicating the specific customers and the rows corresponding with the 205 studied features,

- to identify similarities between customers. In this case of analysis the matrix should be transposed (customers described by rows, features in columns).

\section{FEATURE CLUSTERING RESULTS}

In the case of feature clustering the dataset was divided on 6 clusters numbered from 0 to 5 . Each of the clusters contains observation with similar values assigned by the users of the Xpertis ERP. Table II presents brief statistic characteristics of each cluster. As it can be easily seen from the Figure 1 (which is graphical representation of the data from the Table 2) the clusters differ markedly from each other. Also discrepancy in the average evaluation for each cluster can be seen.

Cluster 5 (Table III) contains attributes which are mostly irrelevant for the evaluation of the system or describe the areas that are not influenced by the system. The attributes in the cluster 5 describe the following areas:

- recycling (all the attributes from this group),

- human Resources and Payroll, - 3 attributes,

- accounting and finance (2 attributes).

The aforementioned attributes from the cluster 5 indicate that the companies do not involve in the recycling activities and do not see the need to support this area by ICT tools.

The other area in this cluster is human resources management. This one is probably seen as a diverse collection of "soft" skills that can be hardly supported by IT tools. The system could be extended by the functions of replacement workforce management in the area of registering the profiles of employees and job seekers. Additionally the decision support tools could be implemented to the recruitment process to make it more effective at getting the best person for a job or a project.
TABLE III.

THE ATTRIBUTES IN CLUSTER 5 - MOSTLY IRRELEVANT

\begin{tabular}{|l|l|}
\hline Area & Attributes \\
\hline Recycling & $\begin{array}{l}\text { Compliance with business requirements } \\
\text { Compliance with strategy } \\
\text { Matching to business processes and functions } \\
\text { Overall user satisfaction } \\
\text { Ease of use } \\
\text { Matching functional requirements (does the } \\
\text { system support all the user's tasks) } \\
\text { Interface - user-friendliness }\end{array}$ \\
& $\begin{array}{l}\text { User support in problem solving } \\
\text { User's autonomy (the need for intervention of } \\
\text { the system administrator) } \\
\text { Visual appeal of the printed documents } \\
\text { Evidence of post-consumer waste } \\
\text { Evidence of revenue resulting from the post- } \\
\text { consumer waste. } \\
\text { Cooperation with recycling companies } \\
\text { Recycling rates } \\
\text { Recycling costs } \\
\text { Cost and time planning } \\
\text { Compliance with legal regulations }\end{array}$ \\
\hline Accounting \\
and finance
\end{tabular}

Source: Own elaboration

Cluster 4 represents the areas on which the ERP system does not have the clear impact or the impact is slightly positive. The system attributes in this cluster are presented in the table IV.

TABLE IV.

THE ATTRIBUTES IN CLUSTER 4 - NO CLEAR IMPACT OR SLIGHTLY POSITIVE EVALUATION

\begin{tabular}{|c|c|}
\hline Area & Attributes \\
\hline \multirow[t]{2}{*}{ Production } & $\begin{array}{l}\text { User's autonomy (the need for intervention of the } \\
\text { system administrator) }\end{array}$ \\
\hline & $\begin{array}{l}\text { Integration of technical and administration areas } \\
\text { (toolroom) }\end{array}$ \\
\hline \multirow[t]{2}{*}{ Sales } & $\begin{array}{l}\text { Easiness and speed of planning (ie. visits to } \\
\text { customers) }\end{array}$ \\
\hline & Speed of handling the users' complaints \\
\hline $\begin{array}{l}\text { After-sales } \\
\text { services: }\end{array}$ & User's autonomy \\
\hline Marketing & $\begin{array}{l}\text { Increased number of non-electronic customer } \\
\text { orders }\end{array}$ \\
\hline Procurement & $\begin{array}{l}\text { Reduction of prices of supplies (by increased } \\
\text { competition between suppliers) } \\
\text { Identification of delays and their causes }\end{array}$ \\
\hline $\begin{array}{l}\text { Warehouse } \\
\text { management: }\end{array}$ & $\begin{array}{l}\text { Loss of value of commodities under storage } \\
\text { use of storage space }\end{array}$ \\
\hline Organization & Creation of the e-communities of employees \\
\hline
\end{tabular}

Source: Own elaboration 
Analyzing the results of the evaluation we can draft some recommendations and suggestions for changes and further development of the system. In the areas of production and after-sales services there is a need for more user autonomy. However the need for the administrator's intervention was mostly indicated by two of the surveyed companies.

Creation of e-communities seems to be interesting future development direction of the ERP system. E-communities may focus on different aspects of the company's functioning and also support the knowledge flow and retention. There is

TABLE V.

THE ATTRIBUTES IN CLUSTER 3 - MODERATELY GOOD AND VERY GOOD EVALUATION

\begin{tabular}{|c|c|}
\hline Area & Attributes \\
\hline \multirow{2}{*}{$\begin{array}{l}\text { All the areas } \\
\text { apart from } \\
\text { recycling }\end{array}$} & User-friendliness of the interface \\
\hline & Visual appeal of the printed documents \\
\hline $\begin{array}{l}\text { Production - } \\
\text { execution of } \\
\text { orders }\end{array}$ & Work planning \\
\hline \multirow[t]{2}{*}{ Sales } & The User's autonomy \\
\hline & Document automation \\
\hline \multirow[t]{4}{*}{ Marketing } & User's autonomy \\
\hline & Increasing number of contractors \\
\hline & Increasing the number of customers \\
\hline & $\begin{array}{l}\text { Quick response for the customers' needs (new } \\
\text { products offerings) }\end{array}$ \\
\hline \multirow[t]{3}{*}{ Procurement } & The User's autonomy \\
\hline & $\begin{array}{l}\text { Increasing number of contractors (wider choice of } \\
\text { raw materials and manufacturing tools) }\end{array}$ \\
\hline & Differentiation of suppliers \\
\hline $\begin{array}{l}\text { Warehouse } \\
\text { management }\end{array}$ & The User's autonomy \\
\hline $\begin{array}{l}\text { Economic } \\
\text { analyses }\end{array}$ & The User's autonomy \\
\hline \multirow[t]{2}{*}{ Organization } & The User's autonomy \\
\hline & Corporate dictionaries \\
\hline $\begin{array}{l}\text { Human } \\
\text { Resources and } \\
\text { payroll }\end{array}$ & The User's autonomy \\
\hline $\begin{array}{l}\text { Accounting } \\
\text { and finance }\end{array}$ & The User's autonomy \\
\hline
\end{tabular}

Source: Own elaboration

a movement taking place in the IT industry that is really driven by major consumer technology vendors like Apple, Google, and Facebook. In fact, employees and managers of most any business are already communicating with each other through various Web 2.0 technologies. However all of this communication is taking place outside the bounds of formal and secure IT systems [1]. Adding collaborative Web 2.0 technologies to ERP applications could be a way to address these challenges both for business users and IT.
The cluster 3 is characterized by moderately good $(75,6 \%)$ and very good (19,4\%).evaluation of the Xpertis ERP features. There are 36 elements in the cluster 3 - mainly the features associated with the user's interface and visual aspects (Table V).

Although the overall assessment is positive there are also signals pointing to the problems regarding the users' autonomy in different modules of the system. This may indicate the poor practical skills and theoretical background of some of the users. The lowest ratings $(-2)$ were given by

TABLE VI .

THE ATTRIBUTES IN CLUSTER 2 - GOOD AND VERY GOOD EVALUATION

\begin{tabular}{|c|c|}
\hline Area & Attributes \\
\hline $\begin{array}{l}\text { All the areas } \\
\text { apart from } \\
\text { recycling }\end{array}$ & Compliance with the business strategy \\
\hline \multirow{2}{*}{$\begin{array}{l}\text { Production - } \\
\text { execution of } \\
\text { orders }\end{array}$} & Lower production costs \\
\hline & Decreased number of production downtimes \\
\hline \multirow[t]{6}{*}{ Sales } & Acceleration of the sales process \\
\hline & Automation of notifications \\
\hline & Number of orders \\
\hline & Number of completed orders \\
\hline & Acceleration of orders completion \\
\hline & The time of answering for the customer's questions \\
\hline \multirow[t]{8}{*}{$\begin{array}{l}\text { After-sales } \\
\text { services }\end{array}$} & $\begin{array}{l}\text { Compliance with business requirements (pre } \\
\text { implementation analysis) }\end{array}$ \\
\hline & Functional adjustment to the processes \\
\hline & Ease of use \\
\hline & Information on the customer's complaints \\
\hline & Identification of problems \\
\hline & Decreased cost of after-sales services \\
\hline & Loyalty systems and analysis of their effectiveness \\
\hline & Revenues from after-sales service \\
\hline \multirow{7}{*}{$\begin{array}{l}\text { Warehouse } \\
\text { management }\end{array}$} & Virtual warehouses \\
\hline & Decrease in stocks \\
\hline & Costs savings on warehousing \\
\hline & Decrease in the storage period \\
\hline & Reduced time of warehousing operations \\
\hline & Reduced costs of non-moving articles \\
\hline & Using data collectors \\
\hline Organization & Project management support \\
\hline \multirow{2}{*}{$\begin{array}{l}\text { Accounting } \\
\text { and finance }\end{array}$} & Information on effectiveness of resources \\
\hline & $\begin{array}{l}\text { Increase in the financial revenue and decrease of } \\
\text { loan service costs }\end{array}$ \\
\hline
\end{tabular}

Source: Own elaboration 
the customers who have been using the system for the shortest time ( 3 and 6 months).

This may indicate the need for additional training during the implementation and post-implementation phase.

The Cluster 2 contains attributes associated with all the areas of the companies' activities (apart from recycling). The relevant areas and attributes are presented in the Table VI.

As it can be seen from the survey results the users evaluation is good or very good for most of the attributes in this cluster. However there are also 5 attributes that received mainly 0 , these are the following: "decreased cost of after sales services", "loyalty systems and analysis of their effectiveness", "revenues from after-sales service", "project management support", "increase in the financial revenue and decrease of loan service costs". The 0 marks mean that the system does not influence the aforementioned areas. However interpretation of the users' assessment indicates interesting possible ways of enhancing the functionality of the system modules. The CRM module could be extended with the possibility to create targeted loyalty programs with relevant and personalized rewards for the customers. Also project management is not directly supported by any module of the system. The project management support should be offered as an optional module integrated with Human Resources and financial modules. Although for now not all the customers practice project management, this discipline is becoming more widely recognized and used throughout the world [16]. Therefore it can be expected that the enterprise project management support could be one of the important features distinguishing the ERP product.

Cluster 1 (Table VII) contains features that are considered very positively influencing the business (mainly marks 2 and 1). This cluster mainly describes the areas associated with enterprise-wide communication and information management. The Users reported significant improvement in marketing effectiveness and efficiency relative to the performance before the implementation of Xpertis system.

The considered ERP system allows a company to manage its business with potential benefits of improved process flow, reduced inventories, more comprehensive data analysis and better customer service.

The Xpertis system has significant impact on acceleration of information flow, document circulation, reporting and analyses. The four companies of the 10 surveyed, claimed that the system does not influence the number of offers sent to their customers and the number of received responses. This fact can be caused by the business specificity and longterm contracts with their customers.

Cluster 0 is the largest one with 87 factors of the system evaluation. The data in this cluster reflect the very positive or moderately positive impact of the system on the surveyed areas of the business. The cluster contains data associated with 10 modules (apart from the recycling module). The most often appearing features are:

- ease of use,
- overall satisfaction or the users,

- support in problem solving,

- automation and acceleration of the specific operations.

Regarding the large number of factors in this cluster and the limited size of the hereby publication the factors are not listed.

TABLE VII.

THE ATTRIBUTES IN CLUSTER 1 - VERY POSITIVE EVALUATION

\begin{tabular}{|c|c|}
\hline Area & Attributes \\
\hline \multirow[t]{4}{*}{ Marketing } & New medium of communication \\
\hline & Number of offerings sent \\
\hline & Number of responses received \\
\hline & Number of electronic orders \\
\hline Procurement & Acceleration of order completion \\
\hline \multirow{3}{*}{$\begin{array}{l}\text { Warehouse } \\
\text { management }\end{array}$} & Acceleration of stocktaking \\
\hline & Raw materials assigned to specific orders/processes \\
\hline & Materials management according to orders \\
\hline \multirow{2}{*}{$\begin{array}{l}\text { Economic } \\
\text { analyses }\end{array}$} & Greater scope of reporting \\
\hline & Analysis of effectiveness of accessible fixed assets \\
\hline \multirow[t]{2}{*}{ Organization } & Additional communication medium \\
\hline & $\begin{array}{l}\text { Communication regardless of location of the } \\
\text { employees }\end{array}$ \\
\hline $\begin{array}{l}\text { Accounting } \\
\text { and finance }\end{array}$ & Monthly balance sheet and reporting online \\
\hline
\end{tabular}

Source: Own elaboration

The above analysis of the effects of the Xpertis ERP system on the business in 10 surveyed companies, shows that the considered software in most of the cases contributes to an improvement of the users' work in various aspects (communication, reporting, acceleration of operational tasks).

So far the potential areas of weakness seem to be factors from the cluster 5, and 4. Particularly the need for administrator's intervention reported by two of the 10 surveyed companies. To facilitate such analyses in the future some of the factors should be reconsidered in the questionnaire:

- human resources management (probably the problem was framed too broadly),

- creation of replacement workforce and employing the replacement workers in the projects (probably the surveyed companies do not practice project management) 


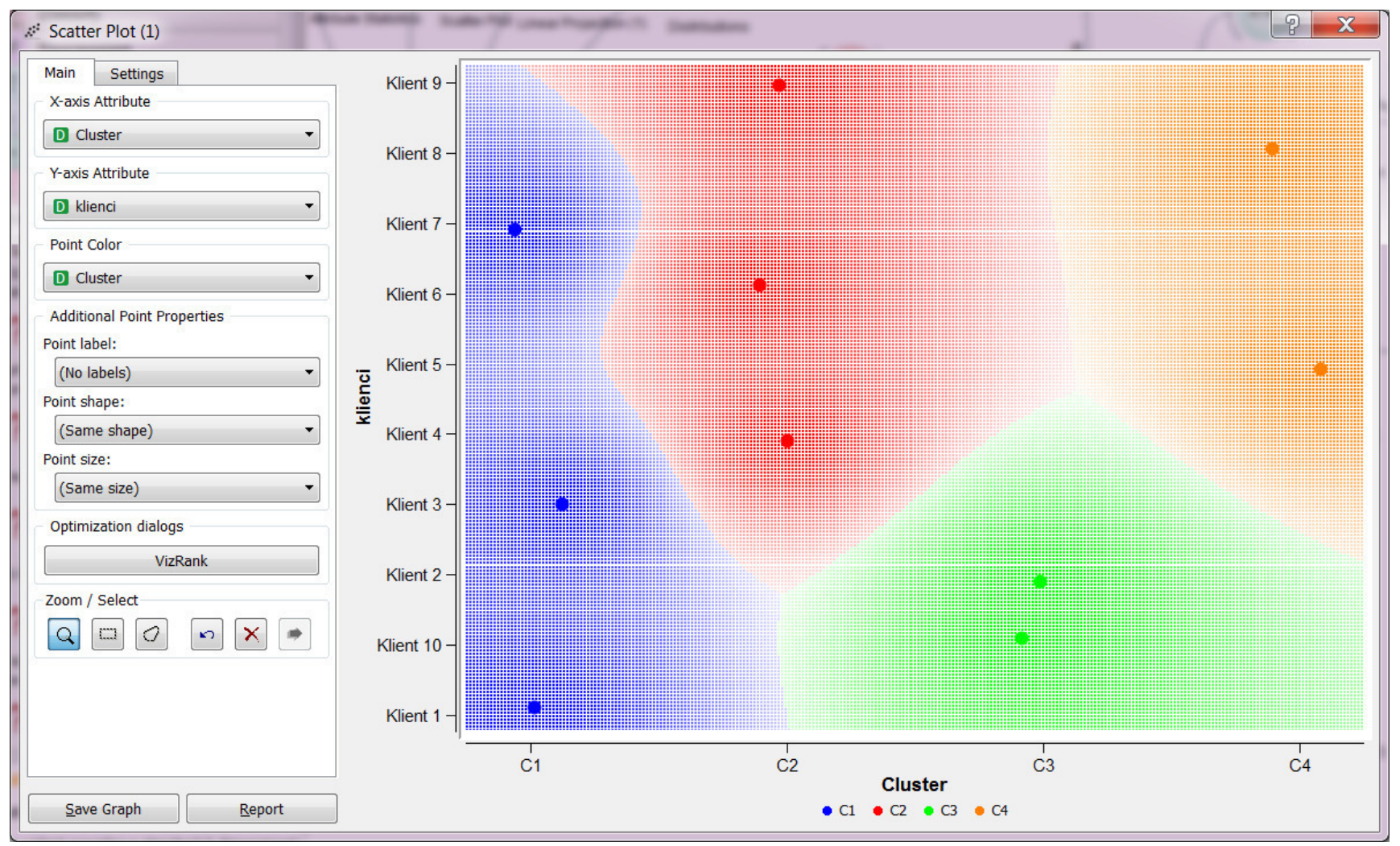

Fig. 3 Customer clusters visualization in Orange Data Mining Software

The question about the system's compliance with business strategy is recognized by the surveyed employees as correlated with the support for operational tasks.

\section{THE CUSTOMERS' CHARACTERISTICS}

In practice of marketing management segmenting is the popular technique of putting customers into groups based on similarities. Segmenting technique assumes the groups are pre-defined. Here we propose clustering method to find similarities in customers so that they can be grouped, and therefore segmented. Then the groups generated by the clustering algorithm undergo semantic interpretation. Semantic interpretation requires some additional insight to find out the reasons of the similarities between the cluster member.

This part of the research approach is aimed at identification and analyses of regularities and similarities between companies exploiting the ERP system.

Although the sample was only 10 companies, the large number of factors taken into consideration makes the problem appropriate for the use of statistical methods. This time the clustering based on k-means algorithm was the choice. The dataset is partitioned into 4 clusters and the data points are randomly assigned to the clusters resulting in clusters that have roughly the same number of data points.
The aforementioned Orange Data Mining tool was used to perform clustering. The Figure 3 presents the visualization of the clusters. The index on the vertical axis refers to the particular customer and the horizontal axis represents the cluster number.

By comparing the data on the time that has elapsed since the completion of the implementation with the clusters created by k-means algorithm it is easy to see some regularities in the evaluations made by customers assigned to the same cluster. It should be noted that the clustering was performed only on the basis of the customers evaluations of the system. Such an approach was taken intentionally to check how far the evaluation depends on the customers' characteristics. The table VIII presents the features of the surveyed Macrologic's customers along with the division on clusters.

A it was mentioned before the customer 5 and 8 reported problems with the users' autonomy, that were caused by little experience because the time after the completion of the system's implementation was relatively short (3 and 6 months). It can be reasonably expected that the evaluation will get better with time. The both observations were located in the cluster 4 . 
Regarding the data in Table VIII it can be assumed that the period of 1 year is the threshold time after which the users get enough experience to easily operate the system. Also the one year of exploitation gives the comprehensible view of achievements of targets assumed in preimplementation phase.

The survey results also show the low evaluation cases in spite of the long post-implementation period (customer 2).
The closer look at the company 1 shows that the customer is very demanding in terms of the IT system and at the same time has very carefully elaborated procedures and is highly aware of the IT capabilities and own expectations. The implementation of the Xpertis system for this customer was difficult and many issues occurred that made it necessary to modify the system or change some process as well as the employees' habits. However the cumbersome and costly

TABLE VIII.

THE ATTRIBUTES OF THE CUSTOMERS

\begin{tabular}{|l|c|c|c|l|}
\hline \multicolumn{1}{|c|}{ Customer } & $\begin{array}{c}\text { Time since ERP } \\
\text { implementation } \\
\text { (months) }\end{array}$ & Cluster & Number of IT staff & Branch \\
\hline Customer 1 & 36 & 1 & 1 & Metallurgy \\
\hline Customer 2 & 36 & 3 & Casual employee & Metallurgy \\
\hline Customer 3 & 12 & 1 & Additionally acting & Chemical \\
\hline Customer 4 & 18 & 2 & 1 & Services, projects \\
\hline Customer 5 & 3 & 4 & 9 & Services \\
\hline Customer 6 & 30 & 2 & 1 & Plastics and paper processing \\
\hline Customer 7 & 20 & 4 & 1 & Metallurgy \\
\hline Customer 8 & 6 & 2 & 2 & Metallurgy, molding \\
\hline Customer 9 & 18 & 3 & 1 & Production, plastics \\
\hline Customer 10 & 12 & 1 & 1 & Furniture \\
\hline
\end{tabular}

Source: Own elaboration

In case of this customer the interview and observation showed the classical example of information asymmetry between the buyer and the vendor of ERP system.

In each of the considered cases the process of implementation had been preceded by pre-implementation analyses and the Xperits system had been customized to fit the customer's needs and business specificity. The information asymmetry could be eliminated or at least mitigated by devoting more time to discussions, consulting and collaboration between the vendor and the buyer. On the other hand it would significantly extend the time and increase the costs of the ERP implementation. The time-cost tradeoff problem is an important issue in the scheduling the large information system implementations.

By considering available data regarding the specificity of the surveyed companies along with the evaluations of the ERP system it can be found that there is no clear dependence between branch of industry and the customer perception of the system. For example the customer 1 and 8 both represent the metallurgic industry, however their production is different. Their evaluations of the system are very divergent so they were assigned to the different clusters and represented by the two points on figure 2 that are far apart from each other. implementation resulted in achieving of the expected results and now after the 36 months of exploitation the system is considered as very valuable for the company.

Another example that proves the hypothesis of interdependence of time factor and the user's evaluation of the system is cluster 2 which contains two customers (9 and 4). Both customers evaluations were similar and the time after the completion of implementation is 18 months in both cases. The clear correlation between the number of IT staff, the form of employment and the customers' evaluations could not be identified.

\section{VIII.CONCLUSION}

The problem of post-implementation analysis of the ERP systems deserves further exploration. The study presented in the hereby paper is an attempt to elaborate the easy to use methodology for the software vendors to get more insight about their customers' needs and the possibilities of improvement of their products. The main issues in the ERP implementations seem to be precise description of the customer expectations and confronting it with the system capabilities. The approach presented hereby let the vendor create an insight on the overall system features in a way that does not reveal private information of the investigated 
companies. Therefore the research results can be presented to potential customers to better illustrate the areas of the impact of the ERP system on business processes.

The cluster analysis is an easy to use and flexible method to discover structures in a data set however it does not provide any explanation itself. The semantic interpretation of clustering effects can be performed by combining the data of each cluster with the knowledge of experienced members of the implementation team. The exploited tool - Orange Data Mining is free and easy to use because it is based on visual data modeling.

The analysis presented in this paper could be extended further to identify more similarities between the customers and the specific modules of the ERP system. For example clustering can be performed to analyze the features of each separate module. Such analysis only requires to prepare the data set limited to the selected features. The new dataset can be then easily loaded to the model built in Orange Data Mining tool.

The approach presented in this paper could be an inspiration for small and medium software companies to elaborate their own methods for products evaluation and comparison of their customers. The sophisticated research approaches based on data mining are often considered as reserved for large businesses with expansive budgets and creative departments. However, with open source data visualization and analysis tools available it is easier than ever for small and medium companies to gain knowledge on their products and customers to let them more effectively compete with larger companies on software market.

\section{ACKNOWLEDGMENT}

The survey prepared is a collaborative effort. Therefore the author thanks Cezary Stępniak for the idea of the research and cooperation on preparation of the survey questionnaire. The author would like to thank Janusz Jakóbczak consultant to the Management Board of Macrologic Inc. for consulting the survey questionnaire, gathering data and his comments to the draft of the paper.

\section{REFERENCES}

[1] Anderson D., Enterprise 2.0 and social media coming to ERP, InfoWorld Dec 22, 2010, retrieved may 02, .2015 from: http://www.infoworld.com/article/2624804/erp/enterprise-2-0-andsocial-media-coming-to-erp.html

[2] Berezowska J., Huet M., Kamińska M., Kwiatkowska M., Orczykowska M., Rozkrut D, Wegner M., Społeczeństwo informacyjne w Polsce Wyniki badań statystycznych. Główny Urząd Statystyczny Urząd Statystyczny w Szczecinie 2014

[3] Demšar, T. Curk J.T., and Erjavec, A. Orange: Data Mining Toolbox in Python; Journal of Machine Learning Research 14(Aug):2349-2353, 2013

[4] Dyczkowski M., Korczak J., Dudycz H., Multi-criteria evaluation of BI systems. The case study of InKoM dashboard, [in] Prace Naukowe Informatyka Ekonomiczna, Business Informatics, 2014 (in print).

[5] Frauendorf, J. Customer processes in business-to-business service transactions. Wiesbaden: Deutscher Universitts-Verlag 2006.
[6] Gudbrod, R.. Wiele, C.: The Software Dilemma: Balancing Creativity and Control on the Path to Sustainable Software. Springer, Berlin 2012

[7] Hong Tang, S., Homayouni, M. and Alaei, H., The role of intelligent agents in customer knowledge management. African Journal of Business Management Vol. 5(16), 18 August, 2011, 7042-7049

[8] Hsu, P., Commodity or Competitive Advantage? Analysis of the ERP Value Paradox," Electronic Commerce and Research and Applications, Vol. 12, No. 6, 2013, pp. 412-424

[9] Hutt M.D., e-Study Guide for: Business Marketing Management: B2B 10th Edition Study Guide, Cram101 Textbooks Reviews 2012

[10] ISO. 1997. ISO9241-11: Ergonomic requirements for office work with visual display terminals (VDT's). Part 11-guidelines for specifying and measuring usability. International Standards Organization (ISO). Available at:http retrieved may 02, .2015 from: http://www.iso.org/iso/iso_catalogue/catalogue_tc/catalogue_detail.ht $\mathrm{m}$ ?csnumber $=16883$.

[11] Jenatabadi, H.S. and A. Noudoostbeni,, End-User Satisfaction in ERP System: Application of Logit Modeling. Applied Mathematical Sciences, 2014. 8 (24): p. 1187-1192.

[12] Kot, E. M. "How to Conduct the Audit of Intellectual Capital in Polish Tourism Business?" Electronic Journal of Knowledge Management Volume 7 Issue 4,(pp459 - 468), Retrieved May 2015 at: www.ejkm.com/issue/download.html?idArticle $=197$

[13] Leyh, C., Critical Success Factors for ERP Projects in Small and Medium-sized Enterprises - The Perspective of Selected German SMEs. In: Proceedings of the 2014 Federated Conference on Computer Science and Information Systems, FedCSIS 2014, September 6 - 10, Warsaw, Poland, pp. 1181-1190. https://fedcsis.org/proceedings/2014/pliks/243.pdf

[14] Mejssner B., Mniejsze przedsiębiorstwa w kolejce po ERP, $\begin{array}{llll}\text { Computerworld } & 16 & \text { April } & 2014\end{array}$ http://www.computerworld.pl/artykuly/395608/Mniejsze.przedsiebior stwa.w.kolejce.po.ERP.html

[15] Nekvasil M., Evaluation of Semantic Applications for Enterprises, Prague, $2010 \quad$ Retrieved from: http://nekvasil.eu/files/papers/1012\%20-

$\% 20$ dissertation $\% 20$ thesis $\% 20$ -

$\% 20$ Evaluation $\% 20$ of $\% 20$ Semantic\%20Applications $\% 20$ for $\% 20$ Ente rprises.pdf

[16] Newell, M. W., and Grashina, M. N. (2004). The project management question and answer book. New York, NY: AMACOM

[17] Ngai EWT, Law CCH, Wat FKT. Examining the critical success factors in the adoption of enterprise resource planning. Computers in Industry; 2008, 59:548-564.

[18] Senathiraja R., Fernando M.D., An Emperical Study on the Impact of Multiple Intelligences on Team Development in The IT Industry in Sri Lanka, South East Asia Journal of Contemporary Business, Economics and Law, Vol. 2, Issue 1 (June) 2013 p.47-58

[19] Shen Y., Software Engineering Challenges in Small Companies Helsinki 2008 http://www.cs.helsinki.fi/u/paakki/Shen.pdf

[20] Scholtz B, Calitz A., Cilliers C., "Usability Evaluation of a Mediumsized ERP System in Higher Education" The Electronic Journal Information Systems Evaluation Volume 16 Issue 22013 , (148-161), Retrieved 01.07.2015 at www.ejise.com

[21] Somers, T.M., and Nelson, K., The Impact of Critical Success Factors across the Stages of Enterprise Resource Planning Implementations'. Proceedings of the 34,h Hawaii International Conference on System Sciences (HICSS-3) Maui, Hawaii. (CD-ROM), January 3-6, 2001.

[22] Stefanou, C. J. 2014, Adoption of Free/Open Source ERP Software by SMEs, in: Information Systems for Small and Medium-sized Enterprises, Devos, J., van Landeghem, H., Deschoolmeester,D. (Eds.) (pp. 157-166): Springer Publishing Company, Incorporated, Berlin, Germany 2014.

[23] Tazyeen F., Modeling government ERP acquisition methods using system dynamics, Massachusetts Institute of Technology 2012, Retrieved may 2015 at: http://web.mit.edu/smadnick/www/wp/201204.pdf

[24] Tchorek-Helm T., Dlaczego firmy nie kupują ERP, 16 June 2011, Retrieved, May 2015 at: http://www.komputerwfirmie.pl/informacje/raporty/pelny/4636/dlacze go-firmy-nie-kupuja-erp 
[25] Vimal, A., Valluri. S.R., Karlapalem. K., An experiment with distance measures clustering. Technical report. Center of Data Engineering. II1T. Hyderabad 2008, retrieved. May 2015 at: http://www.cse.iitb.ac.in/ comad/2008/PDFs/61-ankita.pdf

[26] Wieczorkowski J., Pawełoszek I., Polak P., Software Standardization in the Context of the Innovativeness of Enterprise Operations, in:
P. Kommers, P. Isaias (red.), Proceedings of the International Conference e-Society 2015, s. 215-222, IADIS Press, Lisbon, 2015.

[27] Wieczorkowski J., Polak P., "Analysis and Implementation Phases in the Two-Segmental Model of Information Systems Lifecycle", in 2012 Proceedings of the Federated Conference on Computer Science and Information Systems FedCSIS, PTI, IEEE, Wrocław 2012, pp. 10411046 